\title{
Does Adding of Hydroxychloroquine to the Standard Care Provide any Benefit in Reducing the Mortality among COVID-19 Patients?: a Systematic Review
}

\author{
Tejas K. Patel ${ }^{1}$ (D) $\cdot$ Manish Barvaliya ${ }^{2} \cdot$ Bhavesh D. Kevadiya $^{3} \cdot$ Parvati B. Patel $^{4} \cdot$ Hira Lal Bhalla $^{1}$
}

Received: 22 May 2020 / Accepted: 31 May 2020/Published online: 9 June 2020

(C) Springer Science+Business Media, LLC, part of Springer Nature 2020

\begin{abstract}
Hydroxychloroquine has been promoted for its use in treatment of COVID-19 patients based on in-vitro evidences. We searched the databases to include randomized and observational studies evaluating the effect of Hydroxychloroquine on mortality in COVID-19 patients. The outcome was summarized as odds ratios (OR) with a 95\% confidence interval (CI). We used the inversevariance method with a random effect model and assessed the heterogeneity using $\mathrm{I}^{2}$ test. We used ROBINS-I tool to assess methodological quality of the included studies. We performed the meta-analysis using 'Review manager software version 5.3'. We identified 6 observationalstudies satisfying the selection criteria. In all studies, Hydroxychloroquine was given as add on to the standard care and effect was compared with the standard care alone. A pooled analysis observed 251 deaths in 1331 participants of the Hydroxychloroquine arm and 363 deaths in 1577 participants of the control arm. There was no difference in odds of mortality events amongst Hydroxychloroquine and supportive care arm [1.25 (95\% CI: $\left.0.65,2.38) ; \mathrm{I}^{2}=80 \%\right]$. A similar trend was observed with moderate risk of bias studies [0.95 (95\% CI: $\left.0.44,2.06) ; \mathrm{I}^{2}=85 \%\right]$. The odds of mortality were significantly higher in patients treated with Hydroxychloroquine + Azithromycin than supportive care alone [2.34 (95\% CI: 1.63, $\left.3.34) ; I^{2}=0 \%\right]$. A pooled analysis of recently published studies suggests no additional benefit for reducing mortality in COVID19 patients when Hydroxychloroquine is given as add-on to the standard care.
\end{abstract}

Keywords Hydroxychloroquine $\cdot$ Standard care $\cdot$ COVID-19 $\cdot$ Mortality $\cdot$ Meta-analysis $\cdot$ Azithromycin

\section{Introduction}

Electronic supplementary material The online version of this article (https://doi.org/10.1007/s11481-020-09930-x) contains supplementary material, which is available to authorized users.

Tejas K. Patel

dr.tkp2006@yahoo.co.in

1 Department of Pharmacology, All India Institute of Medical Sciences, Gorakhpur, Gorakhpur, Uttar Pradesh 273008, India

2 Department of Pharmacology, Government Medical College, Bhavnagar, Gujarat 364001, India

3 Department of Radiology, Stanford Medicine, Stanford University, Palo Alto, CA 94304, USA

4 Department of Pharmacology, GMERS Medical College, Gotri, Vadodara, Gujarat 390021, India
Severe acute respiratory syndrome coronavirus 2 (SARSCoV-2) has caused the pandemic of Corona Virus Disease 2019 (COVID-19). In severe cases, it results in acute respiratory distress syndrome, multi-organ failure and death (Zhou et al. 2020). Mortality rate varies from 11.0 to $28.3 \%$ of hospitalized patients (Zhou et al. 2020; Li et al. 2020). The risk of mortality is significantly higher in patients with old age, diabetes mellitus, and concomitant cardiac disease (Zhou et al. 2020; Huang et al. 2020; Inciardi et al. 2020). There is a need for interventions and effective drugs, which can reduce mortality in COVID-19 patients.

In the absence of specific drugs for COVID-19, Hydroxychloroquine is being promoted and used for its treatment based on the results of several in-vitro studies showing the efficacy of chloroquine and Hydroxychloroquine against influenza A and SARS-CoV-2 (Ooi et al. 2006; Vigerust and McCullers 2007; Yao et al. 2020). Chloroquine is suggested 
to prevent viral attachment to host cells, interfere with terminal glycosylation of the cellular receptors, inhibit viral release and to block the production of various cytokines (Ooi et al. 2006; Vigerust and McCullers 2007; Yao et al. 2020; Vincent et al. 2005). Hydroxychloroquine is a hydroxyl analogue of chloroquinethat shares a similar pharmacokinetics and efficacy profile with chloroquine. Animal toxicity studies suggested two to three times less toxicity of hydroxychlorouine than chloroquine (McChesney 1983). Hydroxychloroquine had also shown comparatively less retinal toxicity in humans than chloroquine (Finbloom et al. 1985). Hence, Hydroxychloroquine is preferred over chloroquine and is being utilized more than chloroquine. However, the clinical evidences about its efficacy, especially for reducing mortality rates in COVID-19 patients are limited. Now, some literatures for the effect of Hydroxychloroquine in the treatment of COVID-19 have been started publishing. In this systematic review, we aimed to find out early trends of mortality in COVID-19 patients treated with Hydroxychloroquine based on published literature.

\section{Methods}

We searched PubMed, Google Scholar, medrxiv.org, biorxib. org, mediterranee-infection.com/pre-prints-ihu and CNKI. The search terms were: Hydroxychloroquine, supportive care, mortality, COVID-19, coronavirus, and clinical trial. The last search was run on 13th May 2020. There was no language restriction for inclusion of published articles.

\section{Selection Criteria}

We focused on the comparative clinical studies (randomized and non-randomized) of Hydroxychloroquine with other treatment modalities, conducted on confirmed COVID-19 patients. We considered studies irrespective dose and duration of Hydroxychloroquine. We considered those studies describing mortality as an outcome or provide sufficient data to extract in Hydroxychloroquine and control arms. We excluded non-comparative, in-vitro and animal studies.

\section{Data Extraction}

We extracted following data in a Microsoft Excel sheet, 2016: first author, publication year, country of study site, study design, baseline data in treatment arms (age, gender, severity of disease), Hydroxychloroquine (dosage, duration and route of administration), supportive care, study population characteristics and mortality in treatment arms.

\section{Risk of Bias Assessment of Included Studies}

Two investigators assessed the methodological quality of the included studies as per "risk of bias in non-randomized studies - of interventions (ROBINS-I)” tool (Sterne et al. 2016).

\section{Outcomes and Data Synthesis}

The primary outcome variable was to compare mortality between patients who received Hydroxychloroquine and supportive care at the end of the study period. The secondary outcomes were to compare the mortality between patients who received a) Hydroxychloroquine + Azithromycin and supportive care and b) Hydroxychloroquine + Azithromycin and Hydroxychloroquine alone at the end of the study period. The mortality outcome, a dichotomous variable, was summarized as odds ratio (OR) with $95 \%$ CI. The meta-analytic summary was pooled using the inverse-variance method. We used either fixed or random-effect model based on the heterogeneity present. In the absence of substantial heterogeneity, a fixed-effect model was used to estimate the meta-analytic summary. We assessed heterogeneity using $\mathrm{I}^{2}$ test and publication bias through a 'funnel plot'. We performed a sensitivity analysis of the primary outcome based on the characteristics of study participants (demographics and severity status of participants) and time point for the evaluation of the mortality outcome. In the case of demographics, the primary outcome was estimated by excluding studies with non-comparable age and/gender population in hdroxychloroquine and supportive care arms. Similarly, studies with different severity status population at baseline were excluded. In case of time-point evaluation, studies were divided based on a minimum follow up duration to observe mortality for each patient. It was possible to categorise studies into two groups: $\leq 14$ and $>14$ days follow up duration. It was not possible to perform a sensitivity analysis based on the dose and duration of Hydroxychloroquine, and co-morbidities. We also performed sensitivity analysis of the studies showing the moderate risk of bias in 'overall assessment' of ROBINS-I tool.

The meta-analysis was conducted through 'Review manager software version 5.3'.

\section{Results}

Out of 1902 search items, we retrieved 14 clinical studies (3 randomized and 11 non-randomized) analyzing the effects of Hydroxychloroquine in COVID-19 patients [Fig. 1]. Ten studies were comparative. Three randomized controlled studies reported zero mortality in Hydroxychloroquine and supportive care arms (Chen et al. 2020a, b; Tang et al. 2020). One observational study compared Zinc as add-on to Hydroxychloroquine and Azithromycin (Carlucci et al. 
Fig. 1 Study selection PRISMA flow diagram

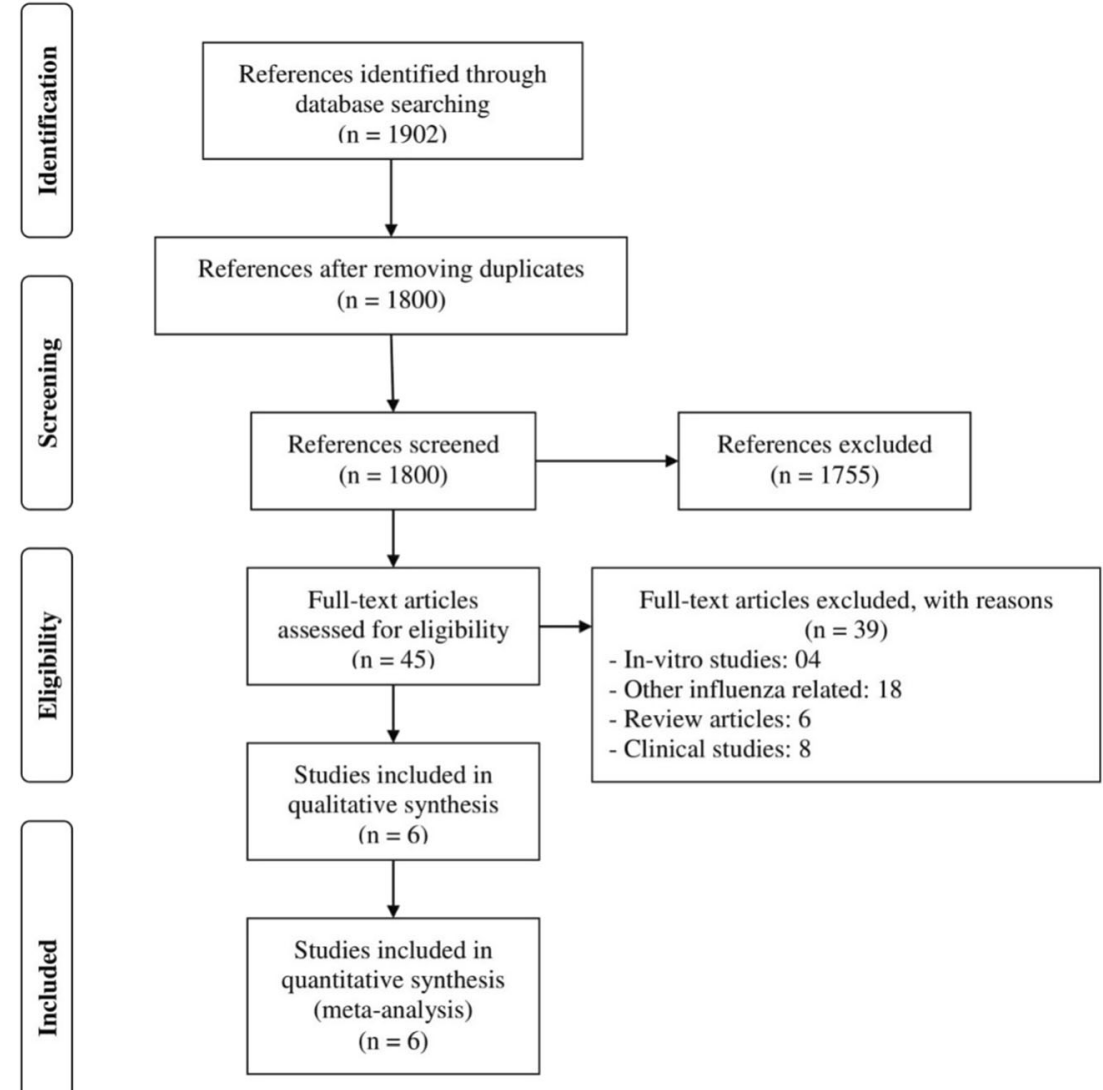

2020). It was possible to extract mortality data of Hydroxychloroquine and control arm in six non-randomized studies (1 prospective, 5 retrospective studies) hence, included in the analysis (Gautret et al. 2020; Geleris et al. 2020; Magagnoli et al. 2020; Mahévas et al. 2020; Rosenberg et al. 2020; Yu et al. 2020).

Table 1 shows the general characteristics of all the included studies like study design, demographics, intervention and severity status details. The findings of risk of bias assessment in individual studies are in Supplementary file (Supplementary Table 1). Four studies were considered of having a moderate risk of bias (Geleris et al. 2020; Mahévas et al. 2020; Rosenberg et al. 2020; Yu et al. 2020) and two were of serious (Gautret et al. 2020; Magagnoli et al. 2020) in the overall assessment.

In Gautret $P$ et al. of 42 patients, 20 patients received Hydroxychloroquine, 6 Hydroxychloroquine + Azithromycin and 16 supportive care treatments. Gautret P et al. excluded 6 patients who received Hydroxychloroquine due to loss to follow up, clinical worsening and death. We considered one death in Hydroxychloroquine arm on day 3 based on the intention to treat principle and included in the study. Gautret $P$ et al. included the patients aged $\geq 18$ years and the age of patients in Hydroxychloroquine-treated arm was higher (51.2 vs. 37.3 years) than the supportive care arm (Gautret et al. 2020).

In the case of Geleris $\mathrm{J}$ et al., 811 patients received Hydroxychloroquine and 565 supportive care. Some of the patients had also received sarilumab, remdesivir and Azithromycin as a part of the treatment. It was not possible to exclude patients receiving other interventions in both arms, and patients who did not receive Hydroxychloroquine were considered as a supportive care group. A total of $85.9 \%$ of patients received Hydroxychloroquine within 48 h of admission to the emergency department. Participants of Hydroxychloroquine and control arms were comparable for the age group and gender. Hydroxychloroquine-treated patients had a lower ratio of arterial oxygen partial pressure to fractional inspired oxygen (Pao2:Fio2) at baseline (median: 233 vs. $360 \mathrm{mmHg}$ ) than control arm patients (Geleris et al. 2020).

In the case of Magagnoli J et al. of 368 patients, 97 patients received Hydroxychloroquine, 113 Hydroxychloroquine + Azithromycin and 158 supportive care treatments. Magagnoli $\mathrm{J}$ et al. included patients with age $\geq 65$ years. All three treatment arms were comparable for age, gender, body mass index, diabetes mellitus, cardiovascular diseases, chronic lung and kidney diseases. However, the proportions of 


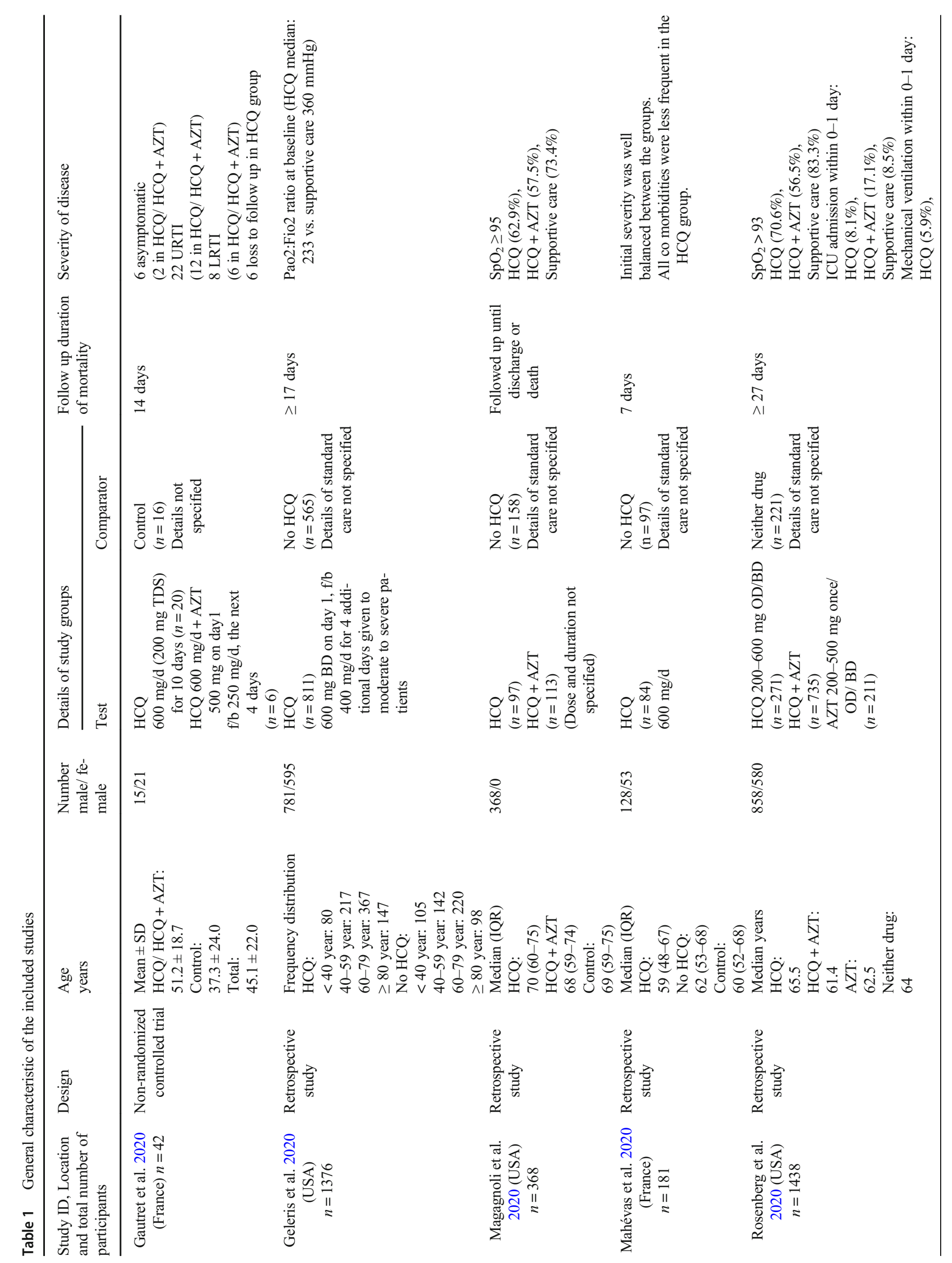




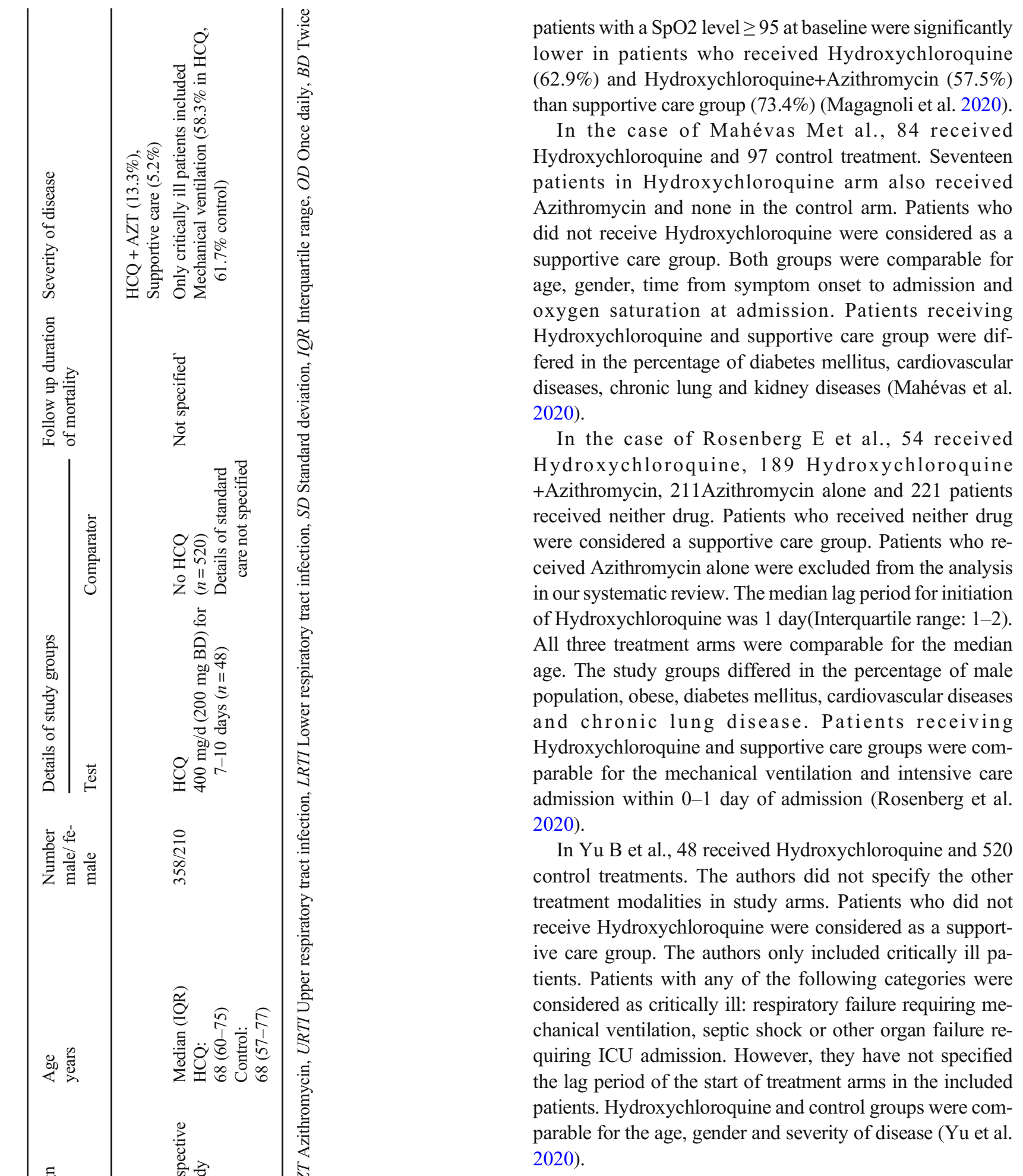

\section{Hydroxychlorpoquine Versus Supportive Care}

Studies reported a total of 251 deaths in 1331 participants of the hydorxychloroquine arm and 363 in 1577 participants of the control arm. Three reported higher odds of mortality with Hydroxychloroquine than supportive care (Geleris et al. 2020; Magagnoli et al. 2020; Rosenberg et al. 2020). In 


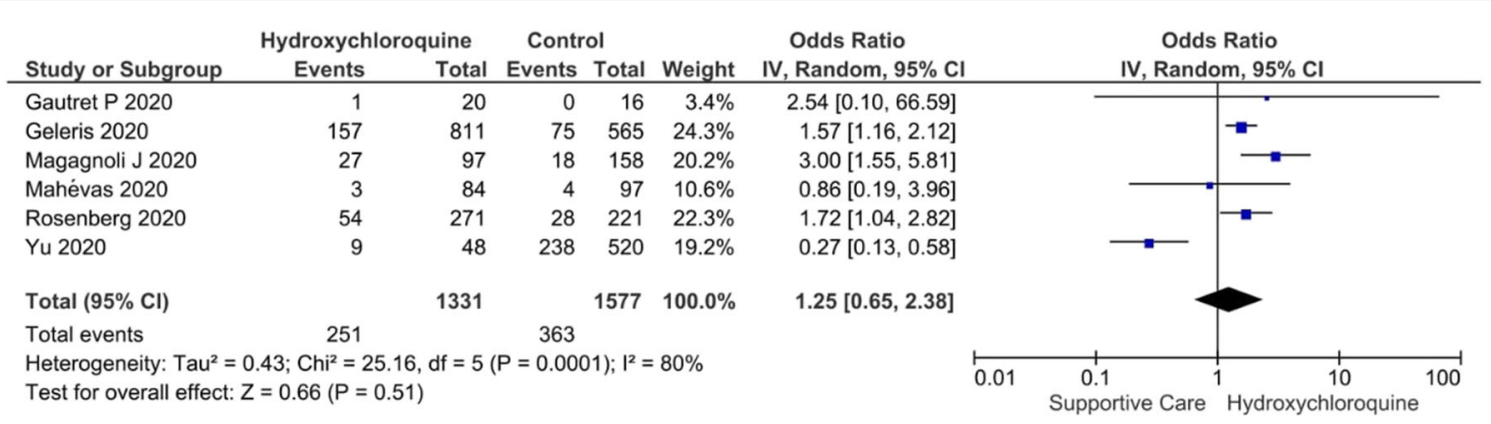

Fig. 2 Meta-analytic summary of mortality data(Hydroxychloroquine versus supportive care) through random effect model

contrast, $\mathrm{Yu} \mathrm{B}$ et al. observed a significant reduction in mortality in patients receiving Hydroxychloroquine than supportive care (Yu et al. 2020). As shown in Fig. 2, the odds of mortality did not differ between Hydroxychloroquine and control arm [1.25 (95\% CI: 0.65, 2.38)]. There was significant heterogeneity $\left(\mathrm{I}^{2}=80 \%\right)$ in this outcome. The funnel plot was asymmetrical on visual inspection [Fig. 3]. Insensitivity analysis, four studies had a comparable study populations concerning age and gender in Hydroxychloroquine and supportive care arm (Geleris et al. 2020; Magagnoli et al. 2020; Mahévas et al. 2020; Yu et al. 2020). Their meta-analytic summary was 1.07 [(95\% CI: $\left.0.41,2.79) \mathrm{I}^{2}=88 \%\right]$. Three studies had comparable severity status of the study population at baseline between Hydroxychloroquine and supportive care arm (Mahévas et al. 2020; Yu et al. 2020). Their meta-analytic summary was 0.74 [(95\% CI: $\left.0.19,2.86), \mathrm{I}^{2}=88 \%\right]$.Two studies each belonged to a minimum follow up duration of $\leq 14$ (Gautret et al. 2020; Mahévas et al. 2020) and >14 days (Geleris et al. 2020; Rosenberg et al. 2020). The other two studies did not specify the participant follow up duration. The meta-analytic of $\leq 14$ and $>14$ days follow up duration studies were 1.05 (95\% CI: 0.26, 4.17), $\mathrm{I}^{2}=0 \%$ ] and 1.24 (95\% CI: $1.24,2.08), I^{2}=0 \%$ ], respectively. The sensitivity analysis of moderate risk of bias studies suggested no difference in odds of mortality between hydrxychloroquine and supportive care $\operatorname{arm}\left[0.95\right.$ [(95\% CI: 0.44, 2.06), $\left.\left.\mathrm{I}^{2}=85 \%\right]\right]$.

\section{Hydorxychloroquine + Azithromycin Versus Supportive Care}

As shown in Fig. 4, three studies reported a total of 214 deaths in 854 participants of the hydorxychloroquine + Azithromycin arm and 46 in 395 participants of the supportive care arm. The odds of mortality were significantly higher in patients receiving hydorxychloroquine + Azithromycin than those who received supportive care [2.34 (95\% CI: 1.63, 3.34); $\left.\mathrm{I}^{2}=0 \%\right]$.

\section{Hydorxychloroquine + Azithromycin Versus Hydroxychloroquine}

As shown in Fig. 5, three studies reported a total of 214 deaths in 854 participants of the Hydroxychloroquine + Azithromycin arm and 81 in 388 participants of the Hydroxychloroquine arm. The odds of mortality did not differ between Hydroxychloroquine + Azithromycin and Hydroxychloroquine arm [1.07 (95\% CI: $0.58,1.98) ; \mathrm{I}^{2}=$ $67 \%]$.
Fig. 3 The funnel plot (Hydroxychloroquine versus supportive care)

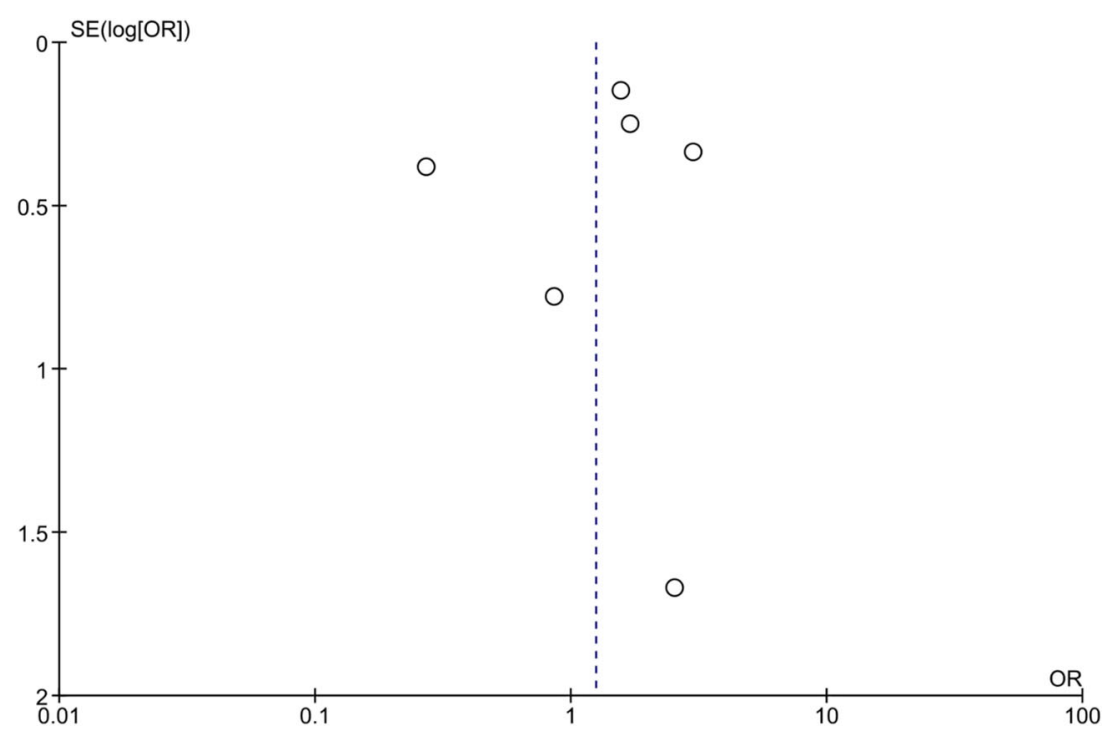




\begin{tabular}{|c|c|c|c|c|c|c|c|c|c|c|}
\hline Study or Subgroup & \multicolumn{2}{|c|}{$H C Q+A Z T$} & \multicolumn{2}{|c|}{ Control } & Weight & $\begin{array}{l}\text { Odds Ratio } \\
\text { IV, Fixed, } 95 \% \mathrm{CI}\end{array}$ & \multicolumn{4}{|c|}{$\begin{array}{c}\text { Odds Ratio } \\
\text { IV, Fixed, } 95 \% \mathrm{Cl}\end{array}$} \\
\hline Gautret P 2020 & 0 & 6 & 0 & 16 & & Not estimable & & & & \\
\hline Magagnoli J 2020 & 25 & 113 & 18 & 158 & $29.6 \%$ & $2.21[1.14,4.28]$ & & & & \\
\hline Rosenberg 2020 & 189 & 735 & 28 & 221 & $70.4 \%$ & $2.39[1.55,3.67]$ & & & & \\
\hline Total $(95 \% \mathrm{Cl})$ & & 854 & & 395 & $100.0 \%$ & $2.33[1.63,3.34]$ & & & & \\
\hline Total events & 214 & & 46 & & & & & & & \\
\hline $\begin{array}{l}\text { Heterogeneity: } \mathrm{Chi}^{2}= \\
\text { Test for overall effect: }\end{array}$ & $\begin{array}{l}.04, \mathrm{df}=1 \\
=4.61(\mathrm{~F}\end{array}$ & $\begin{array}{l}1(P=0 \\
0<0.00\end{array}$ & $\begin{array}{l}.85) ; I^{2}=( \\
001)\end{array}$ & & & & 0.01 & $\begin{array}{l}0.1 \\
\text { pportive Care }\end{array}$ & ${ }^{H C Q}{ }^{10}{ }^{10}$ & 100 \\
\hline
\end{tabular}

Fig. 4 Meta-analytic summary of mortality data (Hydroxychloroquine+Azithromycin versus supportive care) through fixed effect model

\section{Discussion}

The present meta-analytic summary emphasizes a cautious approach in the widespread clinical use of Hydroxychloroquine \pm Azithromycin in the absence of clinical evidence of its efficacy in randomized controlled trials. There is tremendous pressure on health care professionals and researchers across the world to curb the effect of SARS$\mathrm{CoV}-2$. Being highly contagious and associated with higher mortality demand the early identification of effective interventions, including therapeutics and vaccines. It has promoted the widespread use of various treatment modalities based on invitro evidences. Hydroxychloroquine is one of such treatment modalities, which is being given priority due to its proven and known safety records of its use in patients of malaria, systematic lupus erythematous, and rheumatoid arthritis. However, the present meta-analytic summary of six observational studies suggests that the use of Hydroxychloroquine did not reduce mortality in COVID-19 patients. A similar trend was observed with the moderate risk of bias studies. The sensitivity analysis of studies based on demographics, severity status and shorter duration follow up suggest trend of no benefit with the use of Hydroxychloroquine. Studies of longer duration follow-up (>14 days) suggest trends of higher mortality in Hydroxychloroquine arm. It emphasizes the need for active monitoring of mortality data and risk-benefit ratio from ongoing randomized studies of Hydroxychloroquine in COVID-19 patients. The future studies should have longer duration follow up of the mortality data.

There is a possibility of doing more harm than providing the benefits with the use of Hydroxychloroquine especially with the addition of Azithromycin. The risk of mortality was significantly higher in patients who received
Hydroxychloroquine as well as Azithromycin. Three included studies of United State suggest a higher risk of mortality due to Hydroxychloroquine, while one Chinese study suggests its possible benefit. This could be because of different dose, duration and selection of patients in Hydroxychloroquine arm. Included studies used Hydroxychloroquine arbitrarily. They could have varying strategy of its use, or its selection based on discretion of treating physician. However, it represents the outcome of real-world practice with the use of Hydroxychloroquine. This simply cannot be ignored just of the non-randomized nature of the studies especially, when cardiac safety issues raised with its use with Azithromycin in COVID-19 patients. Two recent observational studies reported significant QT interval prolongation with increasing drug exposure (Ramireddy et al. 2020; Chorin et al. 2020). Studies reported one or two out of ten COVID-19 patients treated with Hydroxychloroquine \pm Azithromycin developed critical QT interval prolongation. The risk of cardiac toxicity is higher with the combination of Hydroxychloroquine and Azithromycin. These patients were at risk of developing tachyarrhythmia (Ramireddy et al. 2020; Chorin et al. 2020). Similarly, Rosenberg E et al. reported overall significantly higher percentage of arrhythmia in patients who treated with hydorxychloroquine+Azithromycin $(20.4 \%)$ than Hydroxychloroquine alone (16.2\%) and supportive care (10.4\%) (Ramireddy et al. 2020). A recently, the US FDA has advised the caution against use of Hydroxychloroquine for COVID-19 outside of the hospital setting or a clinical trial due to risk of cardiac arrhythmias (US FDA 2020).

The clinical evidences of randomized controlled trials are not unidirectional (Chen et al. 2020a, b; Tang et al. 2020). They do not suggest a clear benefit of hydrpxychloroquine in COVID-19 patients. They showed no benefits of

\begin{tabular}{|c|c|c|c|c|c|c|c|c|c|c|}
\hline Study or Subgroup & \multicolumn{2}{|c|}{$H C Q+A Z T$} & \multicolumn{2}{|c|}{ HCQ } & Weight & $\begin{array}{c}\text { Odds Ratio } \\
\text { IV, Random, } 95 \% \mathrm{Cl} \\
\end{array}$ & \multicolumn{4}{|c|}{$\begin{array}{c}\text { Odds Ratio } \\
\text { IV, Random, } 95 \% \mathrm{CI}\end{array}$} \\
\hline Gautret P 2020 & 0 & 6 & 0 & 20 & & Not estimable & & & & \\
\hline Magagnoli J 2020 & 25 & 113 & 27 & 97 & $41.0 \%$ & $0.74[0.39,1.38]$ & & & & \\
\hline Rosenberg 2020 & 189 & 735 & 54 & 271 & $59.0 \%$ & $1.39[0.99,1.96]$ & & & & \\
\hline Total $(95 \% \mathrm{Cl})$ & & 854 & & 388 & $100.0 \%$ & $1.07[0.58,1.98]$ & & & & \\
\hline Total events & 214 & & 81 & & & & & & & \\
\hline $\begin{array}{l}\text { Heterogeneity: } \mathrm{Tau}^{2}= \\
\text { Test for overall effect: }\end{array}$ & $\begin{array}{l}0.14 ; \mathrm{Chi}^{2} \\
Z=0.22(\end{array}$ & $\begin{array}{l}=3.04 \\
=0.8\end{array}$ & $\begin{array}{l}d f=1(P \\
3)\end{array}$ & $=0.08$ & $3) ;\left.\right|^{2}=67 \%$ & & 0.01 & 0.1 & $\mathrm{HCQ}^{1} \mathrm{HCQ}+\mathrm{AZT}{ }^{10}$ & 100 \\
\hline
\end{tabular}

Fig. 5 Meta-analytic summary of mortality data(Hydroxychloroquine+Azithromycin versus Hydroxychloroquine) through random effect model 
Hydroxychloroquine with respect to virological cure (Chen et al. 2020a; Tang et al. 2020). They showed conflicting results with the symptomatic relief (Chen et al. 2020a; Tang et al. 2020). Chen $\mathrm{J}$ et al. did not observe a difference in alleviation of fever between hydroxychlorquine and supportive care. Chen $\mathrm{Z}$ et al. and Tang $\mathrm{W}$ et al. observed an earlier symptomatic relief in hydrpxychloroquine-treated than supportive care treated patients.

This study has several limitations. The findings are based on observational studies. Baseline characteristics are less likely to be comparable in observational than clinical trials. The currently published RCTs of Hydroxychloroquine were of open labelled in design and of the small sample size to report mortality data. We have not studied other parameters like virological and clinical improvements. Our findings on mortality should be interpreted cautiously due to the inclusion of studies with differences in age group, co-morbidity, cointerventions and severity of disease in Hydroxychloroquine and supportive care patients. Evidence from multi-centric double blind randomized controlled trial should be confirmatory in this regards.

In conclusion, current evidence suggests hydroxychlorouine did not improve mortality outcome in COVID-19 patients. Patients who received Hydroxychloroquine and Azithromycin are at higher risk of mortality than those who received neither of these drugs. This combination should be avoided in the treatment of COVID-19 patients.

Acknowledgements We are sincerely thankful to Dr. Howard E. Gendelman, Department of Pharmacology and Experimental Neuroscience, College of Medicine, University of Nebraska Medical Center, NE, 68198, USA for his inputs in critical review and editing of this manuscript.

Author Contributions TKP, MB, BDK, PBP and HLB designed the systematic review. TKP and $\mathrm{MB}$ conducted the literature search and extracted the data. TKP, MB and PBP analyzed the data. TKP, MB, BDK, PBP and HLB interpreted the data. TKP wrote the first draft and revised subsequent drafts with the inputs of MB, BDK, PBP and HLB.

\section{Compliance with Ethical Standards}

Conflict of Interest None to declare.

\section{References}

Carlucci P, Ahuja T, Petrilli CM, Rajagopalan H, Jones S, Rahimian J (2020) Hydroxychloroquine and azithromycin plus zinc vs Hydroxychloroquine and azithromycin alone: outcomes in hospitalized COVID-19 patients. MedRxiv https://www.medrxiv.org/ content/10.1101/2020.05.02.20080036v1. Accessed 10 May 2020

Chen J, Liu D, Lui L et al (2020a) A pilot study of Hydroxychloroquine in treatment of patients with common coronavirus disease-19 (COVID-19). Journal of Zhejiang University
Chen Z, Hu J, Zhang Z et al (2020b) Efficacy of Hydroxychloroquine in patients with COVID-19: results of a randomized clinical trial. Version 2. medRxiv 2020.03.22.20040758. [Preprint.] https://doi. org/10.1101/2020.03.22.20040758

Chorin E, Wadhwani L, Magnani S et al (2020) QT interval prolongation and torsade De pointes in patients with COVID-19 treated with Hydroxychloroquine/azithromycin. MedRxiv $2020 \mathrm{https}: / / \mathrm{www}$. medrxiv.org/content/10.1101/2020.04.27.20074583v1. Accessed 10 May 2020

Finbloom DS, Silver K, Newsome DA, Gunkel R (1985) Comparison of Hydroxychloroquine and chloroquine use and the development of retinal toxicity. J Rheumatol 12(4):692-694

Gautret P, Lagier JC, Parola P et al (2020) Hydroxychloroquine and Azithromycin as a treatment of COVID-19: results of an openlabel non-randomized clinical trial. Int J Antimicrob Agents: 105949. https://doi.org/10.1016/j.ijantimicag.2020.105949

Geleris J, Sun Y, Platt J, Zucker J, Baldwin M, Hripcsak G, Labella A, Manson DK, Kubin C, Barr RG, Sobieszczyk ME, Schluger NW (2020) Observational study of Hydroxychloroquine in hospitalized patients with Covid-19. N Engl J Med. https://doi.org/10.1056/ NEJMoa2012410

Huang I, Lim MA, Pranata R (2020) Diabetes mellitus is associated with increased mortality and severity of disease in COVID-19 pneumonia - a systematic review, meta-analysis, and meta-regression. Diabetes Metab Syndr 14(4):395-403

Inciardi RM, Adamo M, Lupi L, Cani DS, Di Pasquale M, Tomasoni D et al (2020) Characteristics and outcomes of patients hospitalized for COVID-19 and cardiac disease in northern Italy. Eur Heart J

Li J, Wang X, Chen J, Zhang H, Deng A (2020) Association of ReninAngiotensin System Inhibitors with Severity or risk of death in patients with hypertension hospitalized for coronavirus disease 2019 (COVID-19) infection in Wuhan, China. JAMA Cardiol. https://doi.org/10.1001/jamacardio.2020.1624

Magagnoli J, Narendran S, Pereira F et al (2020) Outcomes of Hydroxychloroquine usage in United States veterans hospitalized with Covid-19. MedRxiv Available from: https://www.medrxiv. org/content/10.1101/2020.04.16.20065920v1. Accessed 28 Apr 2020

Mahévas M, Tran V, Roumier M, Chabrol A et al (2020) No evidence of clinical efficacy of Hydroxychloroquine in patients hospitalised for COVID-19 infection and requiring oxygen: results of a study using routinely collected data to emulate a target trial. MedRxiv https:// www.medrxiv.org/content/10.1101/2020.04.10.20060699v1.full. pdf. Accessed 10 May 2020

McChesney EW (1983) Animal toxicity and pharmacokinetics of Hydroxychloroquine sulfate. Am J Med 75(1A):11-18

Ooi EE, Chew JS, Loh JP, Chua RC (2006) In vitro inhibition of humaninfluenza a virus replication by chloroquine. Virol J 3:39

Ramireddy A, Chugh HS, Reinier K, et al (2020) Experience with Hydroxychloroquine and azithromycin in the COVID-19 pandemic: implications for QT interval monitoring. MedRxiv https://www. medrxiv.org/content/10.1101/2020.04.22.20075671v1. Accessed 10 May 2020

Rosenberg ES, Dufort EM, Udo T, Wilberschied LA, Kumar J, Tesoriero J, Weinberg P, Kirkwood J, Muse A, DeHovitz J, Blog DS, Hutton B, Holtgrave DR, Zucker HA (2020) Association of Treatment WithHydroxychloroquine or azithromycin with in-hospital mortality in patients with COVID-19 in New York state. JAMA. https://doi. org/10.1001/jama.2020.8630

Sterne JA, Hernán MA, Reeves BC et al (2016) ROBINS-I: a tool for assessing risk of bias in non-randomised studies of interventions. BMJ 355:i4919

Tang W, Cao Z, Han M et al (2020) Hydroxychloroquine in patients with COVID-19: an open-label, randomized, controlled trial. MedRxiv https://www.medrxiv.org/content/10.1101/2020.04.10. 20060558v1.article-metrics. Accessed 28 Apr 2020 
US Food and Drug Administration. FDA cautions against use of Hydroxychloroquine or chloroquine for COVID-19 outside of the hospital setting or a clinical trial due to risk of heart rhythm problems. Available from: https://www.fda.gov/drugs/drug-safety-andavailability/fda-cautions-against-use-Hydroxychloroquine-orchloroquine-covid-19-outside-hospital-setting-or. Accessed 10 May 2020

Vigerust DJ, McCullers JA (2007) Chloroquine is effective against influenza a virus in vitro but not in vivo. Influenza Other Respir Viruses 1(5-6):189-192

Vincent MJ, Bergeron E, Benjannet S, Erickson BR, Rollin PE, Ksiazek TG, Seidah NG, Nichol ST (2005) Chloroquine is a potent inhibitor of SARS coronavirus infection and spread. Virol J 2:69

Yao X, Ye F, Zhang M et al (2020) In vitro antiviral activity and projection of optimized dosing Design of Hydroxychloroquine for the treatment of severe acute respiratory syndrome coronavirus 2 (SARS-CoV-2). Clin Infect Dis. https://doi.org/10.1093/cid/ciaa237 Yu B, Wang DW, Li C (2020) Hydroxychloroquine application is associated with a decreased mortality in critically ill patients with COVID-19. MedRxiv https://www.medrxiv.org/content/10.1101/ 2020.04.27.20073379v1. Accessed 10 May 2020

Zhou F, Yu T, Du R et al (2020) Clinical course and risk factors for mortality of adult inpatients with COVID-19 in Wuhan, China: a retrospective cohort study. Lancet 395(10229):1054-1062

Publisher's Note Springer Nature remains neutral with regard to jurisdictional claims in published maps and institutional affiliations. 